\title{
The parasellar region of human infants: cavernous sinus topography and surgical approaches
}

\section{Wolfgang J. Weninger, M.D., and Gerd B. Müller M.D., Ph.D. \\ Department of Anatomy, University of Vienna, Vienna, Austria}

Object. In this study the authors analyze the peculiarities of the parasellar anatomy and the topography of surgical approaches to the parasellar region (PSR) in human infants.

Methods. Forty-nine specimens of the PSR obtained at autopsy were studied using microdissection and histological analysis. Important distances between anatomical landmarks were measured with the aid of a dissecting microscope. One serially sectioned specimen was three-dimensionally reconstructed and analyzed on the computer screen by using the authors' new episcopic reconstruction technique.

The anatomy of the infant PSR differs distinctly from that of the adult. The parasellar portion of the internal carotid artery (ICA) does not form a siphon, but takes a straight course, and the venous pathways as well as the cranial and sympathetic nerves have different topographical relationships. Analyses of surgical approaches demonstrate that, in young children, the anterolateral approach can be used to reach the pterygopalatine compartment, the superior ophthalmic vein, and those pathological processes that extend from the orbit into the PSR. The approach via Parkinson's triangle can be used in $45 \%$ of cases to access the pathological processes that occur in the voluminous space above and behind the posterior flexure of the parasellar ICA. Taking this route, sympathetic nerve fibers passing through the PSR are not at risk, but some arterial branches that run within the lateral wall of the sinus can complicate this approach.

Conclusions. This study presents a guideline that can assist radiologists and neurosurgeons in the planning and performance of interventions within the PSR of neonates and young children.

Key Words * parasellar region * cavernous sinus * three-dimensional reconstruction * Parkinson's triangle * surgical approach * neonate * children

A number of disease processes occur in the cavernous sinus region of neonates and young children.[2,4,6,11,15,19,46] These often require neurosurgical interventions,[33-36] treatment using invasive radiological techniques,[1,5,29,40] or radiotherapy.[7,9] All manipulations within this narrow space require an exact knowledge of the particular parasellar topography in infants.[33] However, all detailed descriptions of cavernous sinus anatomy,[3,27,31,41,42] measurements of important distances, [14,20-22] and analyses of surgical approaches[8,10,18,32,37,38] have been based on adult specimens. Fetal structures have been studied by Padget,[28] Knosp and associates,16 and Solassol, et 
al.;[39] however, information about structures in young children is scarce. The space lateral to the sella turcica is termed the "parasellar region" and consists of three separate compartments.[45] Exact anatomical descriptions of the peculiar infant topography, pathways for surgical approaches, and measurements of important distances thus far have not been available. The goal of this study is to improve the anatomical knowledge of this confined space and to serve as a guideline for radiologists and neurosurgeons.

\section{MATERIALS AND METHODS}

Forty-nine parasellar regions (PSRs) of human infants, aged between 0 and 9 months (mean 4.3 months) were removed from skull bases at autopsy and were fixed in $3.7 \%$ neutral buffered formaldehyde. Twenty specimens obtained from the left side and 24 from the right side were microdissected, measured, and photographed with the aid of a dissecting microscope. Four other specimens were decalcified in Cal-Ex, dehydrated in ethanol, and embedded in Paraplast. Three of these specimens were sectioned in a coronal plane and one was sectioned in a transverse plane at a 7- $\mu$ m thickness, using a rotation microtome. Subsequently, sections were dyed with standard hematoxylin and eosin, Goldner's, and Mallory's stains.

One specimen (obtained in an infant who died at 3 weeks of age) was reconstructed in a three-dimensional manner on the computer so that our findings could be verified and better visualized. The PSR was dehydrated in saturated ethanol/lead acetate solutions, embedded in paraplast, and sectioned on a specially adapted rotation microtome. After each section had been obtained, the sectioning process was interrupted. The cutting surface of the embedding block was stained with a concentrated sodium sulfide solution and episcopic images of the block surface were captured using a video microscope that was connected to a computer. Subsequently, the contours of bone, nerves, blood vessels, and adipose tissue bodies were outlined in each image by using public domain imaging software. The binary images were transferred to a graphics workstation and were reconstructed in a three-dimensional fashion by using reconstruction software. For details of the technique, see Weninger, et al.[43]

\section{Sources of Supplies and Equipment}

The Wild-Heerbrugg M-8 dissecting microscope, the Leitz rotation microtome (model 1516), and the Reichert-Jung rotation microtome (model 2030) used for the three-dimensional reconstruction were purchased from Leica Microsystems (Wetzlar, Germany). The Cal-Ex was obtained from Fisher Scientific (Orangenburg, NY) and the Paraplast from Sigma Chemical Co. (St. Louis, MO). The Microwatcher VS 90 video was provided by Mitsubishi Corp. (Tokyo, Japan). We used a Macintosh PowerPC 8500/180 computer, obtained from Apple Computer, Inc. (Cupertino, CA) and the Silicon Graphics Workstation (Iris Indigo XL24), obtained from Silicon Graphics, Inc. (Mountain View, CA). Image software, version 1.6, was provided by the National Institutes of Health (Bethesda, MD) and the reconstruction software, Image Volumes, version 2.2, by Minnesota Datametrics (St. Paul, MN).

\section{RESULTS}

\section{Topography of the PSR in Infants}

As in adults, the internal carotid artery (ICA) enters the PSR in infants through the carotid canal and, traditionally, is said to form the carotid siphon. In $92 \%$ of our cases, the angle of the posterior knee of the carotid siphon was greater than 70š; therefore, the parasellar portion of the ICA rarely formed a characteristic siphon in the infant. In $25 \%$ of our cases the course of the ICA was almost completely 
straight with an angle at the posterior knee measuring more than 130 š. We thus use the term "parasellar portion," rather than "carotid siphon" throughout the text. The straight course of the ICA causes a voluminous connective tissue space in the upper posterior portion of the PSR (Fig. 1).

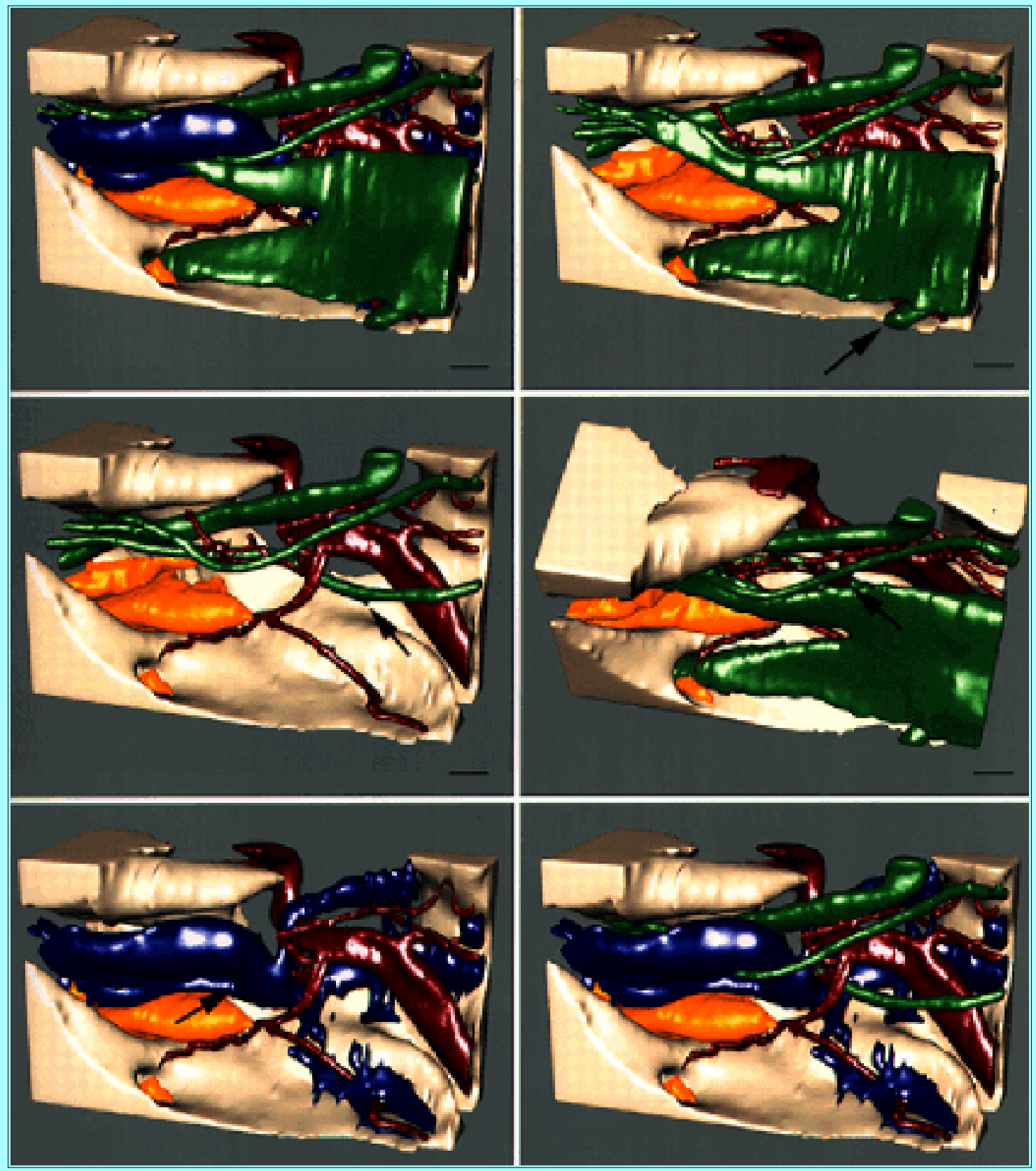

Fig. 1. Three-dimensional reconstructions of a serially sectioned PSR obtained at autopsy from a human infant aged 3 weeks. Oblique lateral views (frontal on left) showing the topographical relationships between the sphenoid bone (tan), cranial nerves (green), veins (blue), arteries (reddish brown), and adipose tissue bodies (yellow). Upper Left: Topography of the lateral wall. The parasellar adipose body can be reached through the anterolateral approach, whereas Parkinson's triangle can be used to reach the meningohypophyseal trunk. Note the course of the superior ophthalmic vein. Upper Right: Cranial nerves of the lateral wall. The ophthalmic and oculomotor nerves ramify within the orbital compartment, which is represented by the orbital adipose body (yellow). Note the motor portion of the trigeminal nerve (arrow). Center Left: Course of the abducent nerve. The anteromedial branch of the inferolateral trunk accompanies the abducent nerve. Although sympathetic nerve fibers were 
not reconstructed, their connection to the abducent nerve is visible in front of the $\mathrm{C}_{5}$ segment of the ICA (arrow). Center Right: Cranial nerves and arteries. Note the inferolateral trunk, which descends between the ophthalmic portion of the trigeminal nerve and the abducent nerve (arrow). Lower Left: Blood vessels of the PSR. The inferior ophthalmic vein (arrow) drains into the superior ophthalmic vein below the anterior knee of the carotid siphon. The arterial trunks of the carotid siphon ramify in the usual manner. Lower Right:

PSR after removement of the trigeminal nerve. Bars $=1 \mathrm{~mm}$.

This space is filled by branches of the artery, the venous plexus, and sometimes by adipose tissue islands (in 33\% of cases). In none of our specimens did any segment of the ICA lie directly adjacent to the lateral wall of the cavernous sinus. The ICA leaves the PSR, perforating the diaphragma sellae medially from the tip of the anterior clinoid process. On average, the center of its lumen is located $5.56 \mathrm{~mm}$ lateral to the median sagittal plane (Table 1).

\begin{tabular}{|c|c|c|}
\hline \multicolumn{3}{|c|}{$\begin{array}{c}\text { TABLE } 1 \\
\text { IMPORTANT DISTANCES BETWEEN ANATOMNAL LANDMARKS IN THE PARASELLAR } \\
\text { REGON OF INFANTS* }\end{array}$} \\
\hline Landmark Distance & $\begin{array}{l}\text { Rt Side (mm] } \\
\text { Mean [range] }\end{array}$ & $\begin{array}{l}\text { Lt Side (mm] } \\
\text { Mean [range] }\end{array}$ \\
\hline 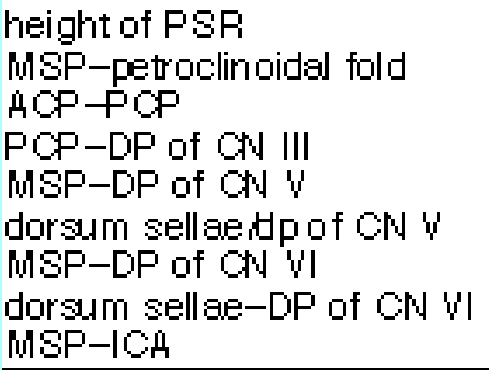 & $\begin{array}{c}13.83(11.1-16.45) \\
8.95(6-13.75) \\
7.93(5.65-10) \\
3.95(2.6-6.55) \dagger \\
10.72(7.75-13.1) \\
9.14(6.8-13.65) \\
6.41(3.9-10.05) \\
11.54(8.8-15.45) \\
5.64(4.25-6.4)\end{array}$ & $\begin{array}{c}13.24(10.45-16.3) \\
9.73(5.6-12.4) \\
8.25(6.15-10) \\
4.02(2.25-5.8) \\
10.79(6.65-14.6) \\
8.76(6.35-10.8) \\
10.58(6.65-14.6) \\
8.62(6-10.8) \\
5.48(4.25-6.95)\end{array}$ \\
\hline \multicolumn{3}{|c|}{$\begin{array}{l}\text { "Note the differences between the right and left sides. Abbre viations: } A C P= \\
\text { anterior clinoid } p \text { roces; } C N=\text { cranial ner've; } D P=\text { dural pore; M } S P=\text { median } \\
\text { sagittal plane; } P C P=\text { posterior dinoid process. } \\
\dagger \text { In front of the } P C P \text {. }\end{array}$} \\
\hline
\end{tabular}

Two large vessels and several small branches originate from the parasellar portion of the ICA (Fig. 1). The small branches arise from the medial surface of the artery and supply the pituitary gland. The meningohypophyseal trunk arises from the vertex of the posterior knee. It ramifies into the clival branch (dorsal meningeal artery), tentorial branch, and inferior hypophyseal artery. The inferolateral trunk originates from the lateral side of the $\mathrm{C}_{4}$ segment and immediately descends to pass between the abducent nerve and the ophthalmic nerve. It divides into the anteromedial branch, which accompanies the abducent nerve, the anterolateral branch, which accompanies the maxillary nerve, the posterior branch, which runs to the mandibular nerve, and the superior branch (Fig. 1). The superior branch ascends occipitally. It runs along the trochlear nerve and reaches the tentorium cerebelli. The superior branch again gives rise to two small branches. One runs lateral to he trochlear nerve, whereas the second crosses Parkinson's triangle obliquely. Sometimes one or even both of them perforate the trochlear nerve (Fig. 2). 


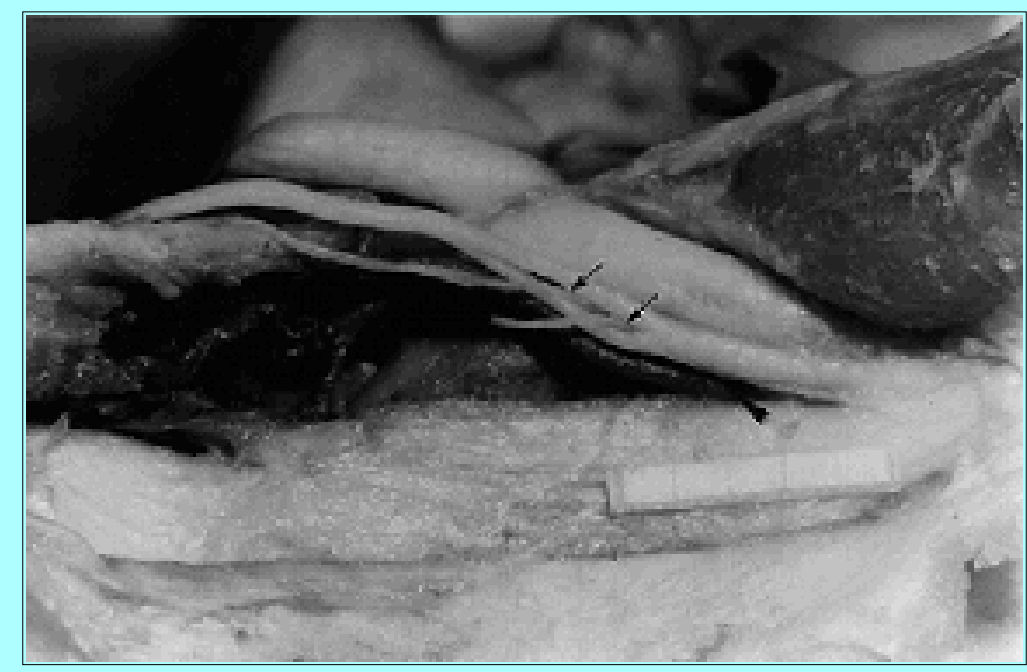

Fig. 2. Photograph showing the course of the superior branch of the inferolateral trunk (arrowhead) (orientation: frontal on right). Two small branches (arrows) perforate the trochlear nerve.

The so-called "cavernous sinus" of infants is not a septate dural space, as described in adults, but consists of individual veins. In the anterior portion of the PSR, a number of small veins lie scattered between the cranial nerves (Fig. 3), whereas the posterior portion of the PSR contains a venous plexus. The superior ophthalmic vein represents the main tributary to this plexus. This large vessel runs along the lateral rim of the superior orbital fissure and enters the PSR below the ophthalmic nerve. Here it is located between the pterygopalatine compartment, which contains the parasellar adipose body, and the orbital compartment, which contains the orbital adipose body (Fig. 3). In front of the anterior knee of the carotid siphon, the ophthalmic vein turns toward the body of the sphenoid bone and continues medially from the ICA (Fig. 1).
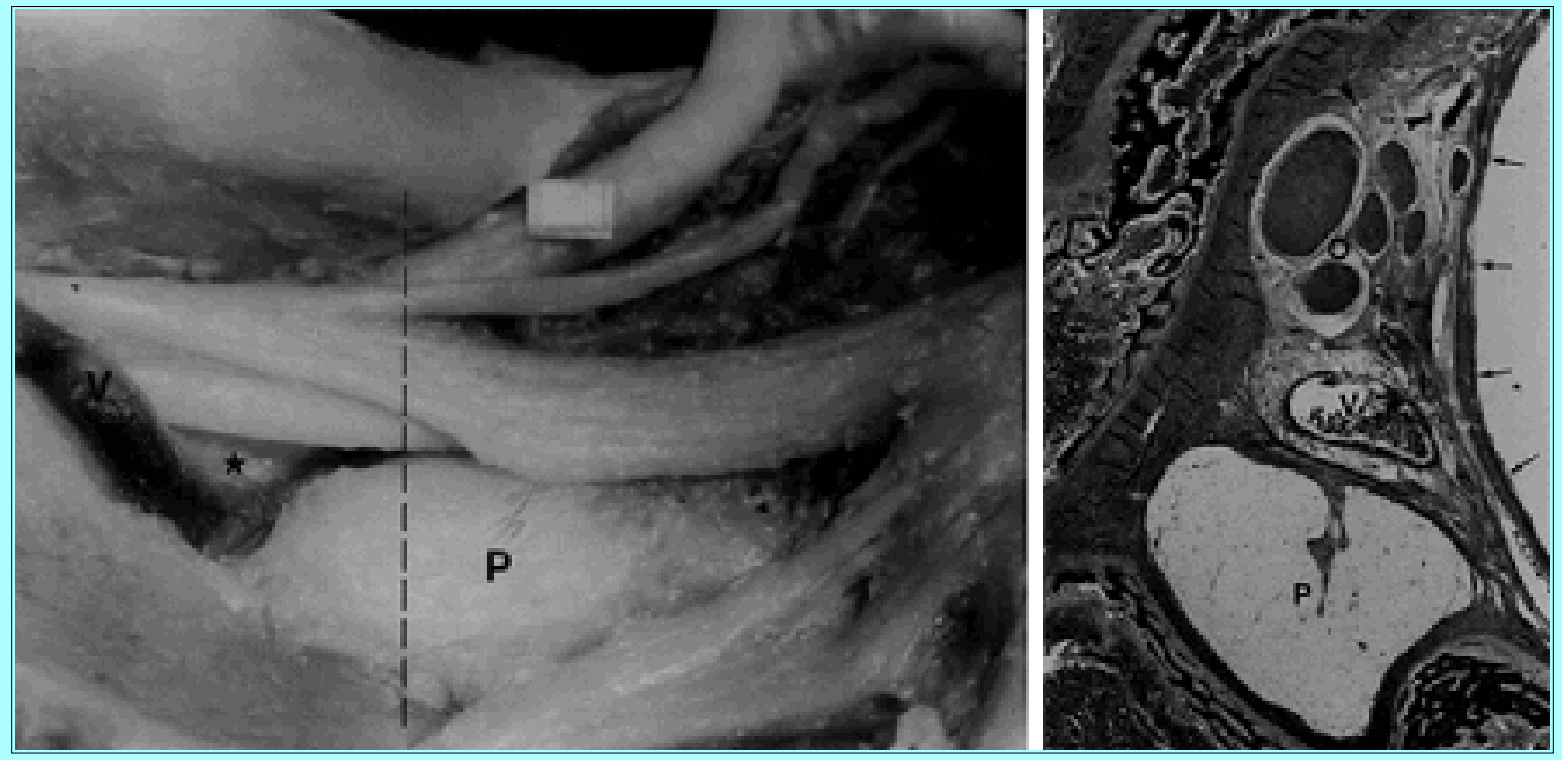

Fig. 3. Photograph and photomicrograph showing the topography of the anterior portion of the PSR. The superior ophthalmic vein (V) is located between the pterygopalatine compartment, which contains the parasellar adipose body $(\mathrm{P})$, and the orbital compartment (O), more frontally located, which contains the orbital adipose body (asterisk). Left: Photograph of gross dissection (orientation: frontal on left). Note the relationship between the abducent and ophthalmic nerves. Right: Photomicrograph showing a frontal section. The 
section plane lies behind the occipital tip of the orbital adipose body. Arrows mark the lateral wall of the PSR. Small veins are scattered between the cranial nerves (arrowheads). Note the ganglion within the parasellar adipose body. Goldner's stain, original magnification X 20.

Very few major deviations from this general blood vessel pattern were observed. The reconstructed specimen (Fig. 1) represented the only case in which the superior ophthalmic vein crossed over the ophthalmic and trochlear nerves. In one dissected specimen, a regularly ramifying inferolateral trunk arose from the meningohypophyseal trunk instead of from the sagittal part of the parasellar portion of the ICA. In another specimen, the ophthalmic artery arose from the ICA within the PSR and, subsequently, entered the orbit via the superior orbital fissure.

\section{Distances Within the PSR in Infants}

The measurements taken from all microdissected specimens provided a number of quantitative data important for neurosurgical approaches and radiological diagnosis. All distances are given as mean values. The distance between the bottom of the medial cranial fossa and the petroclinoidal fold, at the level of the stalk of the pituitary gland, is $13.54 \mathrm{~mm}$. The petroclinoidal fold is situated $9.34 \mathrm{~mm}$ lateral to the median sagittal plane. The distance between the tip of the anterior clinoid process and the tip of the posterior clinoid process measures $8.09 \mathrm{~mm}$.

The oculomotor, trochlear, trigeminal, and abducent nerves pass through the PSR (Fig. 1). Distal to their entrance through "dural pores," they are ensheathed by invaginations of the meningeal dural layer for a few millimeters. The distances between the dural pores and various osseous landmarks are given in Table 1.

\section{Surgical Approaches}

Two lateral approaches to structures inside the PSR are recommended for infants. The lower anterior portion of the PSR can be reached by the anterolateral approach, entering between the ophthalmic and maxillary parts of the trigeminal nerve. The upper posterior portion of the PSR is best reached through Parkinson's triangle, the space between the upper rim of the trigeminal nerve and the lower rim of the trochlear nerve (Fig. 4).

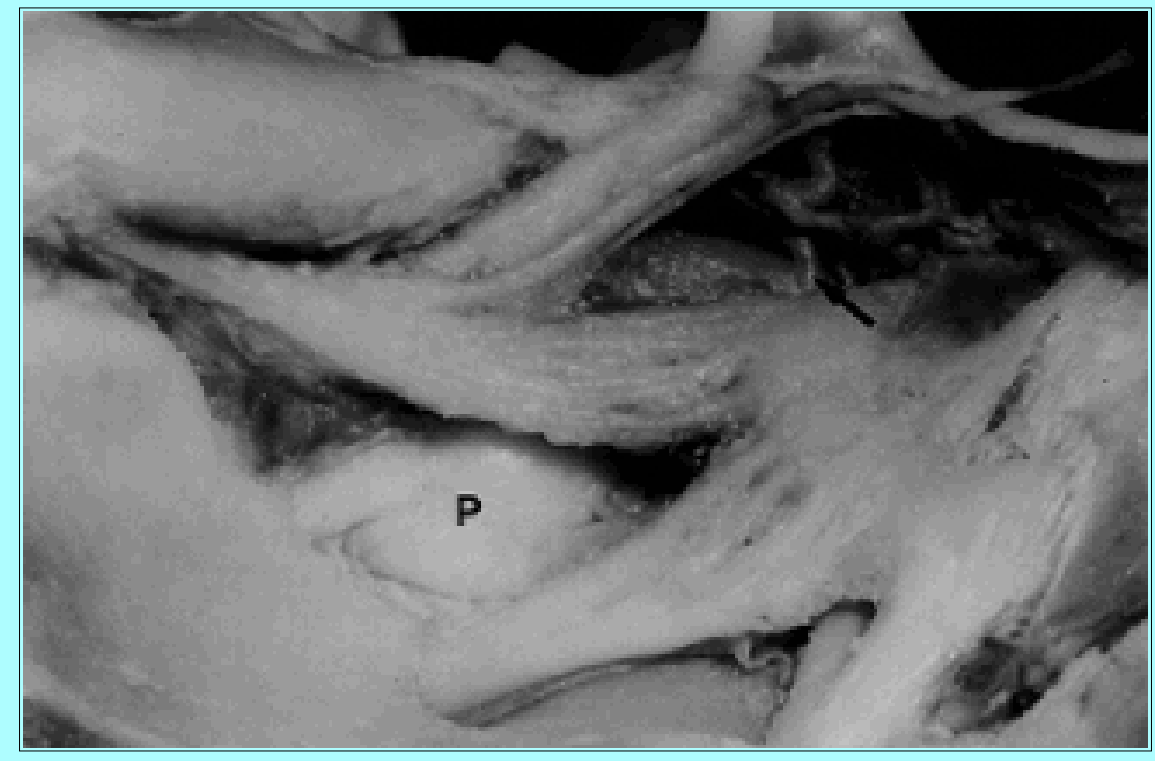


Fig. 4. Photograph showing lateral approaches (orientation: frontal on left). The pterygopalatine compartment, containing the parasellar adipose body $(\mathrm{P})$, and the ophthalmic vein are prepared using the anterolateral approach. The meningohypophyseal trunk (arrow) and its branches are prepared using Parkinson's approach. Note the superior branch of the inferolateral trunk below the trochlear nerve.

Anterolateral Approach. In 80\% of the cases, the pterygopalatine compartment was located immediately underneath the dura mater and had to be opened if the anterolateral approach was used. The pterygopalatine compartment connects to extracranial tissue spaces. It contains the parasellar adipose body (Figs. 3 and 4) and a ganglion that is reached by sympathetic nerve fibers from the internal carotid plexus via the trochlear nerve. The superior ophthalmic vein runs between the pterygopalatine compartment and the orbital compartment (Fig. 3). In each case, this large blood vessel was located immediately underneath the anterolateral wall of the PSR and appeared after the dura mater had been removed.

Parkinson's Triangle. On average, Parkinson's triangle is $3.48 \mathrm{~mm}$ high at the level of the posterior clinoid process. Along the upper rim of the trigeminal nerve the side of this triangle is $7.33 \mathrm{~mm}$ and along the clivus its side is $3.77 \mathrm{~mm}$ long (Fig. 5). The limiting factor for safe approaches toward structures of the upper posterior portion of the PSR is the height of the triangle. Heights greater than 3 $\mathrm{mm}$, as present in $45 \%$ of the cases we examined, allow safe approaches. In $36 \%$ of our cases the height was even greater than $4 \mathrm{~mm}$. In two cases, in which the height of Parkinson's triangle was less than 1 $\mathrm{mm}$, the distance between the oculomotor nerve and the trochlear nerve was $3 \mathrm{~mm}$. These data show that in $50 \%$ of the cases examined in this study the meningohypophyseal trunk, its branches, the site of its origin from the ICA, and the medial wall of the upper posterior portion of the PSR are approachable through Parkinson's triangle (Fig. 5). Most of the sympathetic nerve fibers that pass through the PSR form a common sympathetic trunk medial to the abducent nerve and below the $\mathrm{C}_{4}$ segment of the parasellar portion of the ICA. Therefore sympathetic nerve fibers, which ultimately innervate targets in the orbit, the pineal gland, and the brain, are not at risk when using Parkinson's approach in infants.

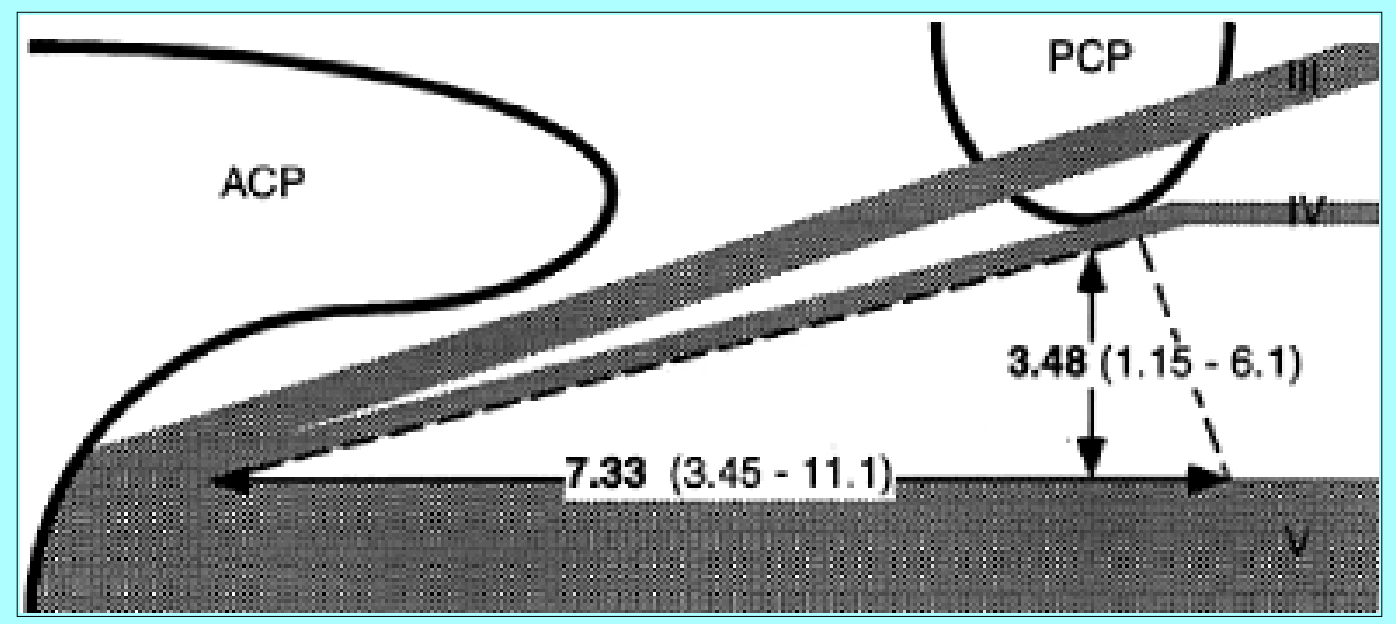

Fig. 5. Schematic drawing showing Parkinson's triangle (orientation: frontal on left). The average height (vertical arrow), average length (horizontal arrow), and ranges of these values (noted in parentheses) are measured in millimeters. The dotted lines mark the clival side and the side along the lower rim of the trochlear nerve (IV). ACP $=$ anterior clinoid process; $\mathrm{PCP}=$ posterior clinoid process; $\mathrm{III}=$ oculomotor nerve $; \mathrm{V}=$ trigeminal nerve. 


\section{DISCUSSION}

Various tumors that occur in the PSR of children during their 1st year of life require surgical treatment.[33-35] In addition to these primary intracranial tumors, a number of pathological processes of the orbital apex can extend into the PSR. They are treated by both ophthalmologists and neurosurgeons.[4,36] As Pikus, et al.,[33] have emphasized, an exact knowledge of the parasellar anatomy is critical for surgical interventions within this space. Extremely careful preparation is necessary because of the limited blood volume and cardiovascular reserve of young children. In this study we present a basis for safe approaches to pathological processes occurring within the PSR of infants.

\section{Topography of the PSR in Infants}

In infants, the space lateral to the sella turcica is preferably called the "parasellar region" and consists of three separate compartments.[45] In adults, the parasellar portion of the ICA forms the carotid siphon.

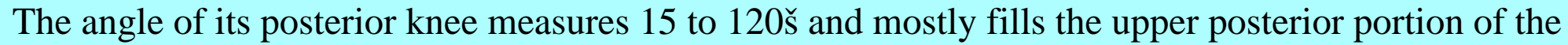
PSR.[27] In contrast, the course of the parasellar portion of the infant ICA is much straighter and, therefore, the upper lateral portion of the PSR is very spacious. The blood vessel is never fully adjacent to the lateral wall of the PSR, as it is in 14\% of adults.[27] The parasellar trunks of the ICA originate and ramify in the same manner as described for fetuses 17 and adults.[25,30] We recognized McConnell's arteries,[26] but their origins were not further analyzed.

In all specimens the occipital portion of the PSR harbored a venous plexus, whereas the frontal portion merely contained some small veins and the large superior ophthalmic vein running between the orbital and pterygopalatine compartments. These findings support earlier notions that reject the presence of a septate cavernous sinus in adults and instead postulate a parasellar venous plexus.[31,41] Cannulation of the superior ophthalmic vein sometimes is used for radiological diagnosis and transvenous treatment of arteriovenous malformations. $[12,13,19]$ The relationship with the pterygopalatine compartment opens the possibility of cannulating the superior ophthalmic vein through the infratemporal fossa via the pterygopalatine compartment or directly through the anterolateral approach.

The positions of the dural pore entrances of the cranial nerves in relation to osseous landmarks differ between adults and children. For example, in adults the dural pore of the oculomotor nerve is mostly situated at the level of the posterior clinoid process or even far behind this process.[20] In contrast, the infant dural pore is always situated in front of the posterior clinoid process (on average $3.99 \mathrm{~mm}$ ). This corresponds to approximately half the distance between the anterior and posterior clinoid processes.

All these anatomical differences between adults and infants demonstrate that the infant's PSR does not represent a small version of the adult cavernous sinus. The osseous structures bordering this space undergo continuous transformations throughout childhood,[24] as do the tissues and structures of the PSR. Therefore, existing topographic analyses of the adult cavernous sinus region do not provide sufficient orientation for neurosurgery and neuroradiology.

\section{Surgical Approaches}

In infants, the anterolateral approach through the triangle between the ophthalmic and the maxillary portions of the trigeminal nerve[37] opens the pterygopalatine compartment and uncovers the superior ophthalmic vein. Through this approach, the frontal portion of the PSR, which contains the parasellar adipose body, the vein and the anterolateral branch of the inferolateral trunk of the ICA can be reached. However, the location of the superior ophthalmic vein, immediately beneath the dura mater in the 
anterolateral approach, may lead to further ideas for using this location for intravascular approaches to the parasellar venous plexus.

Until now, measurements and analyses of surgical approaches made through Parkinson's triangle[32] were only available for adults.[14,21,23] We propose that a height of more than $3 \mathrm{~mm}$ for Parkinson's triangle is the limiting factor for safe approaches and we found distances exceeding this limit in $45 \%$ of our cases. In 5\% of our cases, in which the height was less than $3 \mathrm{~mm}$, the PSR could be approached through the space between the oculomotor and trochlear nerves. Thus, in 50\% of these cases, the upper posterior portion of the PSR could be reached without damaging any cranial nerve. In infants, the parasellar sympathetic pathways to the orbit, brain, and pineal gland form a common sympathetic trunk below the sagittal portion of the parasellar ICA.[44] Thus, they are not at risk when Parkinson's approach is used.

\section{CONCLUSIONS}

Anatomical analyses and measurements of important distances were performed in the infant PSR and were compared with those found in adults. It was found that important differences exist in the composition and topography of blood vessels and nerves. For example, in the infant, the parasellar portion of the ICA is surrounded by a venous plexus and does not form a characteristic siphon; the superior ophthalmic vein is located between the orbital and parasellar adipose bodies before it turns medially to continue between the ICA and the sphenoid bone; the entrance to the dural pore of the oculomotor nerve is situated midway between the anterior and posterior clinoid processes. In addition to these anatomical descriptions, topographical analyses and measurements applicable to the anterolateral surgical approach and to Parkinson's triangle were performed. We describe in detail the structures that can be approached safely through these pathways, as well as situations that may complicate surgical interventions. Thus our study can serve as a guideline for radiologists and neurosurgeons in the treatment of parasellar diseases in neonates and young children.

\section{Acknowledgments}

We thank Christian Reiter and Silvi Rabl for valuable comments, and Bernhard Strauss and Johannes Streicher for technical support.

\section{References}

1. Ahn HS, Kerber CW: Therapeutic embolization of an external carotid-cavernous sinus fistula in an infant. J Neuroradiol 10:261-264, 1983

2. Aoki S, Barkovich AJ, Nishimura K, et al: Neurofibromatosis types 1 and 2: cranial MR findings. Radiology 172:527-534, 1989

3. Bedford MA: The "cavernous" sinus. Br J Ophthalmol 50:41-46, 1966

4. Berlin AJ, Rich LS, Hahn JF: Congenital orbital teratoma. Childs Brain 10:208-216, 1983

5. Biglan AW, Pang D, Shuckett EP, et al: External carotid-cavernous fistula in an infant. Am J Ophthalmol 91:351-356, 1981

6. Brook J, Moss E: Air in the cavernous sinus following scalp vein cannulation. Anaesthesia 
49:219-220, 1994

7. Davidson GS, Hope JK: Meningeal tumors of childhood. Cancer 63:1205-1210, 1989

8. Delfini R, Iannetti G, Belli E, et al: Cranio-facial approaches for tumor involving the anterior half of the skull base. Acta Neurochir 124:53-60, 1993

9. De Salles AAF, Bajada CL, Goetsch S, et al: Radiosurgery of cavernous sinus tumors. Acta Neurochir Suppl 58:101-103, 1993

10. El-Kalliny, van Loveren H, Keller JT, et al: Tumors of the lateral wall of the cavernous sinus. J Neurosurg 77:508-514, 1992

11. Erly WK, Carmody RF, Dryden RM: Orbital histocytosis X. AJNR 16:1258-1261, 1995

12. Gobin YP, Laurent A, Merienne L, et al: Treatment of brain arteriovenous malformations by embolization and radiosurgery. J Neurosurg 85:19-28, 1996

13. Halbach VV, Higashida RT, Hieshima GB, et al: Transvenous embolization of dural fistulas involving the cavernous sinus. AJNR 10:377-383, 1989

14. Harris FS, Rhoton AL Jr: Anatomy of the cavernous sinus. A microsurgical study. J Neurosurg 45:169-180, 1976

15. Hoes MJAJM, Bruyn GW, Vielvoye GJ: The Tolosa-Hunt syndrome--literature review: seven new cases and a hypothesis. Cephalalgia 1:181-194, 1981

16. Knosp E, Müller G, Perneczky A: Anatomical remarks on the fetal cavernous sinus and on the veins of the middle cranial fossa, in Dolenc VV (ed): The Cavernous Sinus. Berlin: Springer-Verlag, 1987, pp 104-116

17. Knosp E, Müller G, Perneczky A: The blood supply of the cranial nerves in the lateral wall of the cavernous sinus, in Dolenc VV (ed): The Cavernous Sinus. Berlin: Springer-Verlag, 1987, pp 104-116

18. Knosp E, Müller G, Perneczky A: The paraclinoid carotid artery: anatomical aspects of a microneurosurgical approach. Neurosurgery 22:896-901, 1988

19. Konishi Y, Hieshima GB, Hara M, et al: Congenital fistula of the dural carotid-cavernous sinus: case report and review of the literature. Neurosurgery 27:120-126, 1990

20. Lang J: Über die Pori durales der Nn. III, IV und VI. Verh Anat Ges 69:785-791, 1975

21. Lang J, Reiter U: Uber den Verlauf der Hirnnerven in der Seitenwand des Sinus cavernosus. Neurochirurgia 27:93-97, 1984

22. Lang J, Reiter U: Uber den Verlauf des N. abducens vor der Austrittszone aus dem zentralnervösen Organ bis zum M. rectus lateralis. Neurochirurgia 28:1-5, 1985

23. Lang J, Reiter W: Praktisch-ärztliche Befunde zum N. trochlearis. J Hirnforsch 27:101-110, 1986

24. Lang J, Zeitler-Zapf P: Uber das relative postnatale Wachstum der Bodenregionen der Fossae craniales. Neurochirurgia 36:179-183, 1993 
25. Lasjaunias P, Moret J, Mink J: The anatomy of the inferolateral trunk (ILT) of the internal carotid artery. Neuroradiology 13:215-220, 1977

26. McConnell EM: The arterial blood supply of the human hypophysis cerebri. Anat Rec 115:175-203, 1953

27. Michailow SS: Makro- und mikroskopische Untersuchungen des baues des Sinus cavernosus. Anat Anz 115:233-255, 1964

28. Padget DH: The cranial venous system in man in reference to development, adult configuration, and relation to the arteries. Am J Anat 98:307-335, 1956

29. Pang D, Kerber C, Biglan AW, et al: External carotid-cavernous fistula in infancy: case report and review of the literature. Neurosurgery 8:212-218, 1981

30. Parkinson D: Collateral circulation of cavernous carotid artery: anatomy. Can J Surg 7:251-268, 1964

31. Parkinson D: Lateral sellar compartment: history and anatomy. J Craniofac Surg 6:55-68, 1995

32. Parkinson D: A surgical approach to the cavernous portion of carotid artery. Anatomical studies and case report. J Neurosurg 23:474-483, 1965

33. Pikus HJ, Holmes B, Harbaugh RE: Teratoma of the cavernous sinus: case report. Neurosurgery 36:1020-1023, 1995

34. Pollack IF, Sekhar LN, Jannetta PJ, et al: Neurilemomas of the trigeminal nerve. J Neurosurgery 70:737-745, 1989

35. Raimondi AJ, Tomita T: Brain tumors during the first year of life. Childs Brain 10:193-207, 1983

36. Rootman J, Kao SCS, Graeb DA: Multidisciplinary approaches to complicated vascular lesions of the orbit. Ophthalmology 99:1440-1446, 1992

37. Sekhar LN, Møller AR: Operative management of tumors involving the cavernous sinus. J

Neurosurg 64:879-889, 1986

38. Sindou M, Chavez JM, Saint Pierre G, et al: Percutaneous biopsy of cavernous sinus tumors through the foramen ovale. Neurosurgery 40:106-111, 1997

39. Solassol A, Zidane C, Slimane-Taleb S, et al: Les veines du sinus caverneux du foetus humain de quatre mois. CR Assoc Anat 149:1009-1015, 1970

40. Takahashi M, Nakano Y: Magnification angiography of dural carotid-cavernous sinus fistulae. With emphasis on clinical and angiographic evolution. Neuroradiology 19:249-256, 1980

41. Taptas JN: The so-called cavernous sinus: a review of the controversy and its implications for neurosurgeons. Neurosurgery 11:712-717, 1982

42. Umansky F, Nathan H: The lateral wall of cavernous venous sinus. With special reference to the nerves related to it. J Neurosurg 56:228-234, 1982 
43. Weninger WJ, Meng S, Streicher J, et al: A new episcopic method for rapid 3D-reconstruction: applications in anatomy and embryology. Anat Embryol 197:341-348, 1998

44. Weninger WJ, Müller GB: The sympathetic nerves of the parasellar region: pathways to the orbit and the brain. Acta Anat 160:254-260, 1997

45. Weninger WJ, Streicher J, Müller GB: Anatomical compartments of the parasellar region: adipose tissue bodies represent intracranial continuations of extracranial spaces. J Anat 191:269-275, 1997

46. Yamamoto T, Asai K, Lin YW, et al: Spontaneous resolution of symptoms in an infant with a congenital dural caroticocavernous fistula. Neuroradiology 37:247-249, 1995

Manuscript received June 19, 1998.

Accepted in final form October 9, 1998.

Address reprint requests to: Wolfgang J. Weninger, M.D., Department of Anatomy, Währingerstrasse 13, A-1090 Vienna, Austria, European Union. email: Wolfgang.Weninger@ univie.ac.at. 